\title{
Air curtain based on coupling of air source heat pump and electric heating
}

\author{
Jin Hongwen ${ }^{1,2}$, song Bingqi ${ }^{1,2}$, Gong Hengqin ${ }^{1,2}$ \\ ${ }^{1}$ College of energy and power engineering, Changchun Institute of technology, Changchun 130012 \\ ${ }^{2} \mathrm{Jilin}$ building energy supply and indoor environment control engineering research center, Changchun 130012
}

\begin{abstract}
Air curtain is a widely used heat insulation equipment in the market, which reduces the heat exchange efficiency of both sides by the air surface formed by jet. In order to reduce the use of electric heating device in air curtain, a new air curtain is designed by the coupling experiment of air source heat pump and electric heating. The air curtain fan is preheated by the condenser of air source heat pump, so as to reduce the dependence of air curtain on electric heating parts, and save energy consumption.
\end{abstract}

\section{Preface}

The air curtain is the air surface formed by the jet from a specific device. The pressure difference between the inside and outside of the air curtain generated by the jet can prevent the gas flow across the jet surface, so as to effectively reduce the mass and energy exchange between the two sides of the air curtain. Air curtain has the advantages of free access, colorless and transparent, smoke and dust isolation, so it is widely used. At present, the air curtain on the market can be divided into electrothermal air curtain, hot water air curtain and steam air curtain according to the heat source. The normal temperature of indoor heating and water supply is about $40{ }^{\circ} \mathrm{C}$, while the temperature of hot water and hot air curtain is about $70{ }^{\circ} \mathrm{C}$. If a heat source is provided for the air curtain alone, the cost will be too high and the economic benefit will be very poor. Steam hot air curtain also needs high steam temperature. If you want to achieve the insulation effect, you also need to set a separate heat source, so it is not very economical. Therefore, the electric air curtain has become the thermal insulation choice for many buildings in winter, but most of the electric air curtain consumes too much power, and the power consumption of the electric air curtain accounts for a large proportion of the whole building power consumption, resulting in a great waste of energy.

Therefore, it is urgent to study the electrothermal air curtain which can save electricity and energy and has more obvious heating effect. An air curtain based on the coupling of air source heat pump and electric heating is designed in this experiment, which uses air source heat pump to heat the air curtain, and the fan outlet air, reduces the use time of electric heating parts of electric heating air curtain, reduces power consumption and saves energy. Improving the energy consumption structure of electric air curtain is of great significance to the development and progress of energy saving technology of air curtain.

\section{Experimental conditions}

The building is a comprehensive service building in Changchun, with a building area of $4092 \mathrm{~m}^{2}$, six floors and a building height of $22.75 \mathrm{~m}$. The main entrance and exit doors of the building are stainless steel glass doors, of which the outer door is $2.4 \mathrm{~m}$ high and $2.7 \mathrm{~m}$ wide; the inner door is $2.1 \mathrm{~m}$ high and $1.5 \mathrm{~m}$ wide.

\section{Load calculation}

\subsection{Calculation of heat consumption of cold air penetration (door gap penetration)}

In the formula:

$$
\mathrm{Q}_{1}=0.278 \mathrm{C}_{\mathrm{p}} \mathrm{V} \rho_{\mathrm{w}} \cdot\left(\mathrm{t}_{\mathrm{n}}-\mathrm{t}_{\mathrm{w}}\right)
$$

$\mathrm{C}_{\mathrm{P}}$ - specific heat capacity of dry air at constant pressure, $\mathrm{C}_{\mathrm{P}}=1.0056 \mathrm{~kJ} /\left(\mathrm{kg} \cdot{ }^{\circ} \mathrm{C}\right)$;

$\mathrm{V}$ - volume flow of cold air penetration in the room, $\mathrm{m}^{3} / \mathrm{h}$;

$\rho_{\mathrm{w}}$ - air density under outdoor heating calculation temperature, $\mathrm{kg} / \mathrm{m}^{3}$;

$t_{n}, t_{w}$ - calculated temperature of indoor and outdoor heating, ${ }^{\circ} \mathrm{C}$.

\subsubsection{Determination of infiltration volume $V$}

$$
\mathrm{V}=\Sigma\left(1 \cdot \mathrm{L}_{0} \cdot \mathrm{m}^{\mathrm{b}}\right)
$$

In the formula:

1 - the length of the gap between the openable doors and windows in a certain direction of the room, $\mathrm{m}$;

$\mathrm{L}_{0}$ - Theoretical infiltration air volume, $\mathrm{m}^{3} /(\mathrm{m} \cdot \mathrm{h})$;

\footnotetext{
*Corresponding author: 380774272@qq.com
} 
$\mathrm{m}$-comprehensive correction coefficient of seepage pressure difference

b - the air permeability index of the gap between the outer window and door, taken as 0.67 .

1) 1 is the length of openable door gap, taking $1=$ $2.7 * 2+2.4 * 3=12.6 \mathrm{~m}$.

2) Determine the theoretical air infiltration rate $L_{0}$

$$
\mathrm{L}_{0}=\alpha_{1}\left(\rho_{\mathrm{w}} \mathrm{v}_{0}^{2} / 2\right)^{\mathrm{b}}
$$

In the formula:

$\alpha_{1}$-permeability coefficient of the gap between the outer doors and windows, $\mathrm{m}^{3} /\left(\mathrm{m} \cdot \mathrm{h} \cdot \mathrm{Pa}^{\mathrm{b}}\right)$;

$\mathrm{v}_{0}$ - average wind speed in winter under the maximum wind direction outside the room, $\mathrm{m} / \mathrm{s}$;

$\rho_{\mathrm{w}}$ - air density under outdoor heating calculation temperature, $\mathrm{kg} / \mathrm{m}^{3}$.

a) The permeability coefficient $\alpha_{1}=0.3$.

b) Because the average wind speed under the maximum outdoor wind direction in Changchun in winter is $\mathrm{v}_{0}=4.7 \mathrm{~m} / \mathrm{s}$, the air density $\rho_{\mathrm{w}}=1.4 \mathrm{~kg} / \mathrm{m}^{3}$ under the calculated temperature of outdoor heating is $-21.1{ }^{\circ} \mathrm{C}$. To sum up, the theoretical air infiltration rate:

$$
\mathrm{L}_{0}=\alpha_{1}\left(\rho_{\mathrm{w}} \mathrm{v}_{0}^{2} / 2\right) \quad \mathrm{b}=0.3 *\left(1.4 * 4.7^{2} / 2\right) \quad 0.67=1.89 \mathrm{~m}^{3 /}
$$

3)The comprehensive correction coefficient $\mathrm{m}$ of seepage pressure difference.

In the formula:

$$
\mathrm{m}=\mathrm{C}_{\tau} \triangle \mathrm{C}_{\mathrm{f}}\left(\mathrm{n}^{1 / \mathrm{b}}+\mathrm{C}\right) \mathrm{C}_{\mathrm{h}}
$$

$\mathrm{C}_{\tau}$-Thermal pressure coefficient. Under the action of pure hot pressure, the percentage of the thermal pressure difference acting on both sides of the outer window and door gap in the total thermal pressure difference of infiltration or seepage is 0.7 ;

$\triangle \mathrm{C}_{\mathrm{f}}$-Coefficient of wind pressure difference. Under the action of pure wind pressure, the wind pressure difference between the two sides of the building is half of that. When it is considered that the resistance of the gap between the outer door and the window on the leeward side is the same, and the aerodynamic coefficients of the leeward side are 1.0 and - 0.4 respectively, the value is 0.7 ;

$\mathrm{n}$-Under the action of pure air pressure, the orientation correction coefficient of infiltration air volume is 0.70 ;

a)C-The ratio of effective thermal pressure difference and effective wind pressure difference acting on both sides of outer door and window gap.

$\mathrm{C}=70\left(\mathrm{t}_{\mathrm{n}}{ }^{\prime}-\mathrm{t}_{\mathrm{w}}\right)\left(\mathrm{h}_{\mathrm{z}}-\mathrm{h}\right) /\left[\Delta \mathrm{C}_{\mathrm{f}} \mathrm{V}_{0}{ }^{2}\left(273+\mathrm{t}_{\mathrm{n}}{ }^{\prime}\right) \mathrm{h}^{0.4}\right]$

In the formula:

$\mathrm{h}_{\mathrm{z}}$ - The elevation of the neutral boundary of the building under the action of pure thermal pressure, $\mathrm{m}$, can be replaced by half of the total height of the building;

$t_{n}$ '-The calculated temperature of the air in the thermal pressure shaft in the building, ${ }^{\circ} \mathrm{C}$. When the corridor and stairwell are not heated, $\mathrm{t}_{\mathrm{n}}{ }^{\prime}$ is taken as the temperature difference correction coefficient, and $16{ }^{\circ} \mathrm{C}$ or $18^{\circ} \mathrm{C}$ for heating;

$\mathrm{t}_{\mathrm{w}}$-Outdoor heating calculation temperature;

$\mathrm{v}_{0}$ - The average wind speed under the most wind direction in winter is $4.7 \mathrm{~m} / \mathrm{s}$.
To sum up the above:

$\mathrm{C}=70 *(16+21.1)^{*}\left(22.75^{*} 0.5-1.2\right) /\left[0.7 * 4.7^{2 *}\right.$

$\left.(273+16) * 1.2^{0.4}\right]=5.5$

b) $\mathrm{C}_{\mathrm{h}}$ - The height correction factor of the height of the outer door and window gap.

$$
\mathrm{C}_{\mathrm{h}}=0.3 \mathrm{~h}^{0.4}=0.3^{*} 1 \cdot 2^{0.4}=0.32
$$

In the formula:

$\mathrm{h}$-Calculate the elevation of the center line of doors and windows, taking $1.2 \mathrm{~m}$.

In the formula, the comprehensive correction coefficient of air seepage pressure difference is obtained $\mathrm{m}=\mathrm{C}_{\tau} \triangle \mathrm{C}_{\mathrm{f}}\left(\mathrm{n}^{1 / \mathrm{b}}+\mathrm{C}\right) \mathrm{C}_{\mathrm{h}}=0.7^{*} 0.7^{*}\left(0.7^{1 / 0.67}+5.5\right)$

$* 0.32=0.95$

Air infiltration

$\mathrm{V}=1 \cdot \mathrm{L}_{0} \cdot \mathrm{m}^{\mathrm{b}}=12.6 * 1.89 * 0.95^{0.67}=23.01 \mathrm{~m}^{3}$

In conclusion, the heat consumption of cold air penetration (door gap penetration)

$\mathrm{Q}_{1}=0.278 \mathrm{C}_{\mathrm{p}} \mathrm{V} \rho \mathrm{w} \cdot(\mathrm{tn}-\mathrm{tw})$

$=0.278 * 1.0056 * 23.01 * 1.4 *(16+21.1)=334.11 \mathrm{~W}$

\section{2 calculation of the heat consumption $Q_{2}$ of the cold air when the outer door is opened}

According to table 5.1-14 in the practical heating and air conditioning design manual, determine the heat consumption $\mathrm{Q}_{2}$ of the cold air when the outer door is opened.

\subsubsection{Calculation of basic heat consumption $Q_{0}$ of main entrance and exit outer door:}

$$
\mathrm{Q}_{0}=\mathrm{kF}\left(\mathrm{t}_{\mathrm{n}}-\mathrm{t}_{\mathrm{w}}\right) \alpha
$$

In the formula:

$\mathrm{Q}_{0}$ - Basic heat consumption of main entrance and exit, W;

$\mathrm{k}$ - Heat transfer coefficient of main entrance and exit, $\mathrm{W} /\left(\mathrm{m}^{2} \cdot{ }^{\circ} \mathrm{C}\right)$;

$\mathrm{F}$ - Heat dissipation area of main entrance and exit outer door, $\mathrm{m}^{2}$;

$\mathrm{t}_{\mathrm{n}}$ - Calculation temperature of indoor air, ${ }^{\circ} \mathrm{C}$;

$t_{\mathrm{w}}$-Outdoor calculation temperature for heating, ${ }^{\circ} \mathrm{C}$;

$\alpha$-The correction coefficient of temperature difference is 1 .

1) According to "practical heating and air conditioning design manual", determine the heat transfer coefficient of the main entrance and exit door $\mathrm{k}=2.5 \mathrm{~W} /$ $\left(\mathrm{m}^{2} \cdot{ }^{\circ} \mathrm{C}\right)$.

2) Heat dissipation area of outer door of main entrance and exit $\mathrm{F}=2.4 * 2.7=6.48 \mathrm{~m}^{2}$

3) Determine the calculated temperature of indoor air according to the design manual of practical heating and air conditioning $\mathrm{t}_{\mathrm{n}}=16^{\circ} \mathrm{C}$.

4) Outdoor calculation temperature for heating $\mathrm{t}_{\mathrm{w}}=-21.1^{\circ} \mathrm{C}$

To sum up, the basic heat consumption of the main entrance and exit outer door

$\mathrm{Q}_{0}=\mathrm{kF}\left(\mathrm{t}_{\mathrm{n}}-\mathrm{t}_{\mathrm{w}}\right) \alpha=2.5 * 6.48 *(16+21.1) * 1=601.02 \mathrm{~W}$ 


\subsubsection{Calculation of the heat consumption Q2 of the cold air when the outer door is opened:}

Because the building is a six story building, the main entrance and exit are double doors, and the outside door is opened to blow in the cold air to consume heat.

$\mathrm{Q}_{2}=\mathrm{Q}_{0} \cdot 80 \% \mathrm{~N} * 2=601.02 * 80 \% * 6 * 2=5769.79 \mathrm{~W}$

\subsection{Total load of the outer door on the first floor of the building}

Heat consumption due to cold air infiltration

$\mathrm{Q}_{1}=334.11 \mathrm{~W}$, heat consumption of cold air when the outer door is opened $\mathrm{Q}_{2}=5769.79 \mathrm{~W}$, Total load of external door on the first floor of building $\mathrm{Q}=\mathrm{Q}_{0}+\mathrm{Q}_{1}+\mathrm{Q}_{2}=601.02+334.11+5769.79=6704.92 \mathrm{~W}$

\section{4 high rise building load}

The building is a six storey comprehensive service center, which is a multi-storey building. Compared with a teaching building in Changchun, the building has 13 floors, the building height is $48 \mathrm{~m}$, the first floor is $4.8 \mathrm{~m}$, and the second-13th floors are $3.6 \mathrm{~m}$. The main entrance and exit door of the building is made of stainless steel glass, with the height of $2.4 \mathrm{~m}$ and the width of $2.7 \mathrm{~m}$. Calculation of heat consumption of cold air infiltration

$$
\mathrm{Q}_{1}=0.278 \mathrm{C}_{\mathrm{p}} \mathrm{V} \rho_{\mathrm{w}} \cdot\left(\mathrm{t}_{\mathrm{n}}-\mathrm{t}_{\mathrm{w}}\right)
$$

$=0.278 * 1.0056 * 38.14 * 1.4 *(16+21.1)=553.80 \mathrm{~W}$

Basic heat consumption of main entrance and exit $\mathrm{Q}_{0}=\mathrm{kF}\left(\mathrm{t}_{\mathrm{n}}-\mathrm{t}_{\mathrm{w}}\right) \alpha=2.5 * 6.48 *(16+21.1)^{*} 1=601.02 \mathrm{~W}$

Heat consumption of cold air when the outer door is opened

$$
\mathrm{Q}_{2}=0.278 \mathrm{C}_{\mathrm{p}} \mathrm{L} \rho_{\mathrm{w}} \cdot\left(\mathrm{t}_{\mathrm{n}}-\mathrm{t}_{\mathrm{w}}\right)
$$

$=0.278 * 1 * 1.2 *(2 * 400 * 3.6) * 37.1=35644.49 \mathrm{~W}$

Total load of outer door on the second floor of teaching building

$$
\mathrm{Q}=\mathrm{Q}_{0}+\mathrm{Q}_{1}+\mathrm{Q}_{2}
$$

$=601.02 \mathrm{~W}+553.80 \mathrm{~W}+35644.49 \mathrm{~W}=36799.31 \mathrm{~W}$

According to the above data results, we can get the load of multi-storey buildings and high-rise buildings in winter, as shown in Table 1.

Table 1. Comparison of cooling load of different buildings in heating season

\begin{tabular}{c|cccc}
\hline Project & $\begin{array}{c}\text { Heat consumption } \\
\text { of cold air } \\
\text { infiltration }\end{array}$ & $\begin{array}{c}\text { Basic heat } \\
\text { consumption of main } \\
\text { entrance and exit }\end{array}$ & $\begin{array}{c}\text { Heat consumption of } \\
\text { cold air when the } \\
\text { outer door is opened }\end{array}$ & $\begin{array}{c}\text { Total load of } \\
\text { outer door }\end{array}$ \\
\hline Multi storey building & $334.11 \mathrm{~W}$ & $601.02 \mathrm{~W}$ & $5769.79 \mathrm{~W}$ & $6704.92 \mathrm{~W}$ \\
High rise building & $553.8 \mathrm{~W}$ & $601.02 \mathrm{~W}$ & $35644.49 \mathrm{~W}$ & $36799.31 \mathrm{~W}$ \\
\hline
\end{tabular}

To sum up, whether it is a multi-storey building or a high-rise building, the invasion of cold air outside the door is large in winter, which leads to high indoor heat consumption, resulting in a great waste of heat. The indoor heating effect of the building can not meet the expected requirements, which has a great impact on people's production and life. Therefore, the use of air curtain to block the outdoor cold wind and protect the indoor heat consumption is a necessary choice for public buildings in severe cold areas. Because the six floor comprehensive service center of the building is equipped with a door bucket, which can form a hot air curtain wall, the air curtain designed in this experiment bears the total load of the heat consumption of the outer door invasion, the heat consumption of the cold air door gap penetration and the basic heat consumption of the outer door.

According to the total load of the outer door of the six floor comprehensive service center of the building, the following is selected:

The external unit of low temperature air source heat pump MAC030ER5SH, internal machine MACS030ER5, heating capacity of $10 \mathrm{~kW}$ and heating power of $3.2 \mathrm{Kw}$. The air curtain is RM-1509-D, the fan power is $180 \mathrm{~W}$ and the heater power is $6-10 \mathrm{kw}$.

\section{5 design structure}

The purpose of the new air curtain design is to preheat the air curtain fan, reduce the use of the electric heating components of the air curtain, reduce the consumption of electricity and reduce the energy waste. The purpose of the new air curtain design is to use the air source heat pump and electric heating coupling air curtain. The condenser in the air source heat pump is assembled in a shell with the fan and the electric heating part. The fan is located on one side of the shell, the condenser and the electric heating part are arranged in the inner cavity of the shell, and the condenser is arranged between the fan and the electric heating part.

Air source heat pump is composed of condenser and evaporator, wherein condenser is connected with evaporator through pipeline, and compressor and throttle valve are arranged on connecting pipeline.

The shell is also provided with a motor which is connected with the fan and drives the fan for operation.

Three thermocouple temperature sensors are arranged at the top of the shell, which are respectively installed at the air outlet of the fan, the end near the condenser in the middle of the condenser and electric heating, and the end of the electric heating part near the air outlet. The three thermocouple temperature sensors are connected to the thermostat through a circuit. 


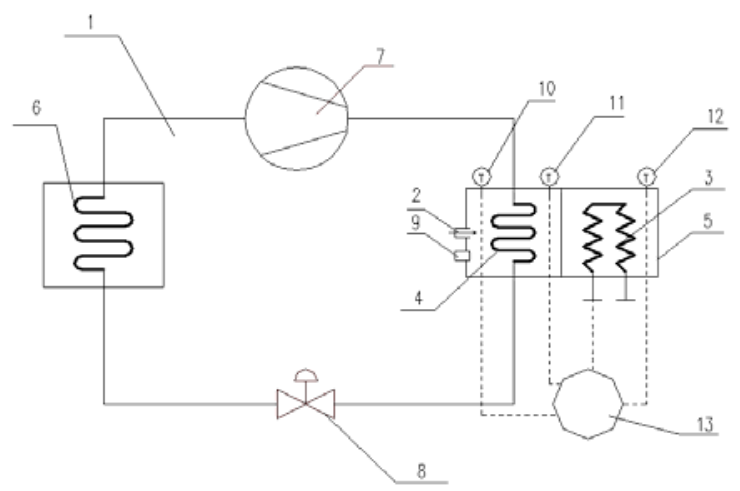

Fig. 1.is a schematic diagram of the air curtain structure based on the coupling of air source heat pump and electric heating. 1-Air source heat pump ;2-fan; 3-electric heating part; 4-condenser; 5-shell; 6-evaporator; 7-Compressor 8-throttle valve; 9-motor : 10、11,12、-thermocouple temperature sensor; 13 -temperature controller

\section{Working principle and energy consumption analysis}

\subsection{Working principle}

When the fan in the air curtain based on the coupling of air source heat pump and electric heating works, the air enters the condenser in the air source heat pump from the fan, and the condenser releases heat, so that the air entering the shell gets heat, and the outlet air temperature in the shell rises.

Under the winter condition, the air curtain fan works, and the thermocouple temperature sensor 10 at the fan outlet records the fan outlet temperature and transmits it to the temperature controller. The outlet air of the fan is heated by the condenser of the air source heat pump, and the air temperature in the device is higher than the outlet air temperature of the fan after being heated by the condenser. The thermocouple temperature sensor 11 continues to record the temperature of the air outlet heated by the condenser and transmit it to the temperature controller. If it meets the design standard and can meet the needs of people's production and life, when the air outlet enters the electric heating parts, the temperature controller controls the electric heating parts not to work, and the air outlet is directly discharged from the air outlet of the shell. If the design standard is not met, the air outlet temperature can not meet the needs of people's production and life. After heating up, the air outlet of the fan is controlled by the temperature controller of the electric heating part, and the air outlet is heated for the second time in the electric heating part. The air outlet of the fan obtains heat, increases the air outlet temperature, and then the temperature is recorded by the thermocouple temperature sensor 12 and transmitted to the temperature controller for discharge.

If the temperature recorded by the thermocouple temperature sensor 12 and transmitted to the temperature controller is greater than $50{ }^{\circ} \mathrm{C}$, the temperature controller controls the electric heating parts to adjust the number of resistance wires to make the outlet temperature reach the standard range.
If the temperature data of thermocouple temperature sensor 10 and thermocouple temperature sensor 11 are the same when the heat pump is working, the temperature of thermocouple temperature sensor 10 and thermocouple temperature sensor 12 are the same when the electric heating component is not working, and the temperature of thermocouple temperature sensor 11 and thermocouple temperature sensor 12 are the same when the electric heating component is working, the thermostat will give an alarm, indicating that there is a component The damage needs repairing.

\section{2 energy consumption analysis}

The normal heating days in Changchun are 169 days, the heating days are from October 20 to April 6, and the extreme weather days are 15 days.

As a heating equipment, low-temperature air source heat pump absorbs low-grade energy in outdoor air and transmits heat to the room through refrigerant. To make refrigerant evaporate and absorb heat at low temperature, outdoor air is conducted with equal humidity cooling (A to $\mathrm{B}$ ) or cooling and dehumidification (A to $\mathrm{C}$ ), as shown in Figure 2.

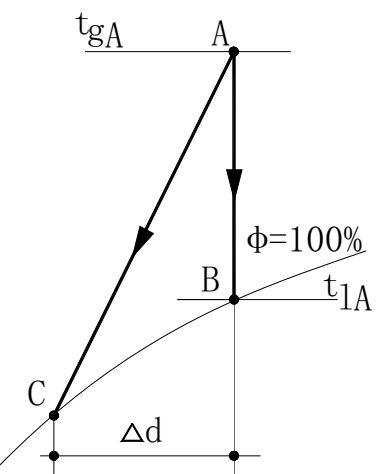

Fig. 2. surface treatment process of outdoor air in heat pump

In theory, when the external surface temperature of the evaporation heat exchanger is lower than the dew point temperature of the outdoor air state point, the surface of the heat exchanger will be frosted (or dewed), so the frosting of the air source is closely related to the outdoor air conditions. The outdoor dry bulb temperature $\operatorname{tg}$ and relative humidity $\varphi$ are important parameters affecting the frosting efficiency of the air source heat pump, and the frosting range temperature is $-12.8^{\circ} \mathrm{C} \leq$ $\operatorname{tg} \leq 5{ }^{\circ} \mathrm{C}$ When $\operatorname{tg}>-5.8{ }^{\circ} \mathrm{C}$, frosting is not considered; when $\operatorname{tg}<5^{\circ} \mathrm{C}$ and relative humidity $\varphi>85 \%$, frosting is serious; when $\operatorname{tg}<-5{ }^{\circ} \mathrm{C}$, frosting rate slows down; when tg $<-5.8^{\circ} \mathrm{C}$ and $\varphi<67 \%$, frosting does not occur; when tg $<-12.8{ }^{\circ} \mathrm{C}$, frosting does not occur. The average relative humidity of outdoor air in heating period of Changchun City is mostly below the limit of relative humidity, and frosting is more serious.

The experimental results show that when the water temperature difference $\Delta t<0.2$, the defrosting time of the heat pump accounts for $1.37 \%$ of the total heating time. Because the heating days in Changchun City are 169 days, the total defrosting time of heat pump is 


\section{$169 \times 24 \times 1.37 \%=55.57 \mathrm{~h}$}

The power consumption of heat pump in the whole heating season is as follows:

$169 \times 3.2 \times 24=12979.2 \mathrm{kWh}$

The power of electric heater is $6-10 \mathrm{kw}$, here $8 \mathrm{kw}$

The power consumption of electric heating components in extremely cold weather is as follows:

$15 \times 24 \times 8=2880 \mathrm{kWh}$

Under normal winter conditions, the power consumption of defrosting electric heating components is as follows:

$$
55.57 \times(154 / 169) \times 8=405.1 \mathrm{kWh}
$$

The power consumption of defrosting electric heating components in extremely cold weather is as follows:

\section{$55.57 \times(15 / 169) \times 8=39.46 \mathrm{kWh}$}

The power of the fan is $180 \mathrm{~W}$, and the power consumption of the whole heating machine is:

$$
0.18 \times 24 \times 169=730.08 \mathrm{kWh}
$$

In the whole heating season, the total power consumption of the air curtain designed by the device is as follows:

$12979.2+2880+405.1+730.08=16994.38 \mathrm{kWh}$

The total power consumption of ordinary electric air curtain in the whole heating season is as follows:

$$
169 \times 24 \times 8+730.08=33178.08 \mathrm{kWh}
$$

From the above data, we can get the power consumption of common air curtain and new air curtain in the whole heating season, as shown in Table 2

Table 2. Comparison of power consumption of common and new air curtain in heating season

\begin{tabular}{c|cccc}
\hline Project & $\begin{array}{c}\text { Heat pump } \\
\text { power } \\
\text { consumption }\end{array}$ & $\begin{array}{c}\text { Electric } \\
\text { heating Power } \\
\text { consumption }\end{array}$ & $\begin{array}{c}\text { Fan } \\
\text { Power } \\
\text { consumption }\end{array}$ & $\begin{array}{c}\text { Power } \\
\text { Consumption }\end{array}$ \\
\hline Ordinary air curtain & - & $32448 \mathrm{kWh}$ & $730.08 \mathrm{kWh}$ & $33178.08 \mathrm{kWh}$ \\
New air curtain & $12979.2 \mathrm{kWh}$ & $3282.47 \mathrm{kWh}$ & $730.08 \mathrm{kWh}$ & $16994.38 \mathrm{kWh}$ \\
\hline
\end{tabular}

\section{Benefit analysis}

\subsection{Economic benefit analysis}

The total electricity saved in the whole heating season is $33178.08-16991.75=16186.33 \mathrm{kWh}$, According to the price of electricity in Changchun, 0.947 yuan per kilowatt hour is taken. Because the heat pump power can be priced separately and the civil electricity price is 0.525 yuan per kilowatt hour,So the whole heating season to save electricity

$16186.33 \times 0.947+12979.2 \times(0.947-0.525)$

$=20805.68$ yuan

The initial investment of the air curtain based on the coupling of air source heat pump and electric heating is about 20000 yuan more than that of the ordinary electric heating air curtain, with an additional air source heat pump, a thermostat and three thermocouple temperature sensors. Basically, the amount of electricity saved in one year can recover the cost.

According to the calculation of $0.404 \mathrm{~kg}$ standard coal per kilowatt hour by the National Bureau of statistics, the whole heating season can save coal for power generation:

\section{$\mathrm{T}=16186.33 \times 0.404=6539.28 \mathrm{~kg}$}

According to the above calculation method, when the building load is $50 \mathrm{KW}$, the heating power of the heat pump is $21.2 \mathrm{kw}$, and the power consumption of the whole heating season is $96280.91 \mathrm{kwh}$. Therefore, the larger the cooling load of the building, the higher the power of the heat pump, and the more considerable the power saving in the heating season of the energy-saving air curtain. As shown in Figure 3.

\section{Quantity of electricity $(\mathrm{kWh})$}

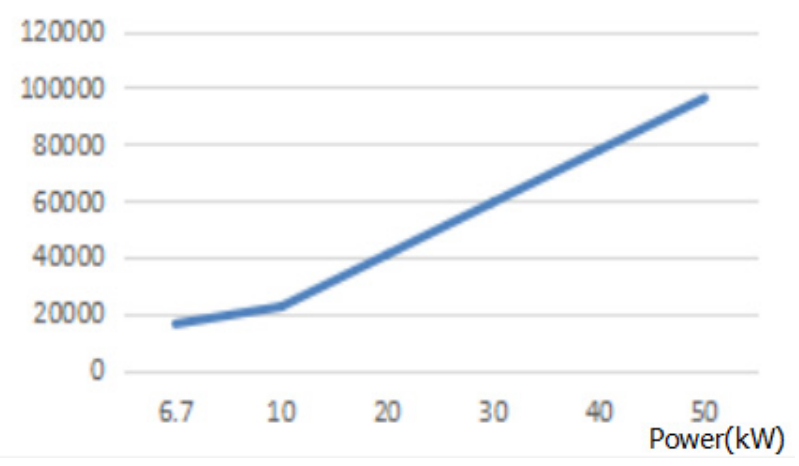

Fig.3. Electricity saved by new air curtain with different building loads in heating season

\section{2 environmental benefit analysis}

According to the data released by the national development and Reform Commission, burning one ton of coal emits 2.62 tons of carbon dioxide, $8.5 \mathrm{Kg}$ of sulfur dioxide and $7.4 \mathrm{~kg}$ of nitrogen oxides. The emission of carbon dioxide, sulfur dioxide and nitrogen oxide can be reduced by $17.13 \mathrm{t}, 55.58 \mathrm{~kg}$ and $48.39 \mathrm{~kg}$ in the whole heating season.

Due to the large building area base in China, with the popularization of air curtain based on the coupling of air source heat pump and electric heating in the whole country, the energy consumption and coal consumption of power generation will be very considerable, and the emission of polluting gases will also be reduced, which will effectively reduce energy consumption and reduce the environmental pollution caused by harmful gases, 
which has great significance for today's increasingly serious pollution significance.

\section{Conclusion}

Compared with the traditional air curtain, the air curtain based on the coupling of air source heat pump and electric heating reduces the service time of electric heating components. If the air curtain temperature formed by the fan heated by the condenser can rise to close to people's living needs, the electric heating components will not work, reducing the consumption of electricity, thus saving energy. In the environment of national energy revolution, the application and promotion of this type of air curtain has a positive practical significance for people's production and life.

\section{References}

1. Lu Yaoqing. Practical heating and air conditioning design manual [M]. 2nd Edition. Beijing: China Construction Industry Press, 2008:18081810

2. He Wuhua, the advantages and disadvantages of R410A refrigerant in multi split unit [J]. Refrigeration, 2006 (1): 72-74

3. Mao Jinfeng, Dou Wenping, Han $\mathrm{Xu}$. Continuous solar heating system for observation tower in plateau cold area [J]. Journal of PLA University of science and technology: Natural Science Edition, 2005 (1): 63-66

4. Jiang Yiqiang, Yao Yang, Ma Zuiliang. Calculation of defrosting loss coefficient of air source heat pump [J]. HVAC, 2000,30 (5): 24-26

5. Jin Hongwen, Sun Yan, Ma Zhe, et al. Research on Application of ultra-low temperature air source heat pump in severe cold area $[\mathrm{J}]$. Journal of Harbin University of Commerce (NATURAL SCIENCE EDITION), 2017,33 (6): 728-731743

6. Wang Wei, Ni long, Ma Zuiliang. Air source heat pump technology and application [J]. Beijing: China Construction Industry Press, 2017,7:5

7. Liu $\mathrm{Yu}$, Wang haolu. Energy saving design of HVAC in industrial building [j]. Equipment management and maintenance, 2020 (20): 179-181

8. Han Yue, Guo Haifeng, chaijiaying. The current research status of air curtain and the prospect of new air curtain [j]. Construction and budget, 2020 (08): 47-50

9. Zhang Bowen, Wang Haining, Zhang Yingbin. Comparison and optimization of ventilation methods between air curtain and jet fan in highway tunnel [j]. Nonferrous metal science and engineering, 2020,11 (03): 80-89

10. Xiao Bei. Feasibility study of compound air curtain in smoke prevention of buildings [j]. Urban buildings, 2020,17 (16): 166-168+174

11. Zhang Shushu. Study on the ventilation of coal mines in high altitude area based on air curtain regulation [d]. Xi'an University of construction technology, 2020

12. Xiaobei, Yang Haozhe, Zhang Hualei. The mechanism of the influence of key parameters of air curtain on smoke control effect in non ideal environment [j]. Energy saving, 2020,39 (05): 143146

13. Ganyangyang, lizhisheng. Air curtain to PM in kitchen_(2.5) simulation and analysis of control effect [j]. Journal of Guangdong University of technology, 2020,37 (03): 82-87

14. Yan David. Application of two parallel air curtain induced air flow in oblique ditch coal mine [j]. Coal mine modernization, 2020 (03): 194-196+199

15. Xiao di. Study on the dust control system and performance of soft seal based on cross flow wind curtain [d]. China University of mining, 2020 